\title{
Gender Differences in Russia's Job Mobility and Its Rewards
}

\author{
Ivan Privalko
}

July 2, 2020

\begin{abstract}
This article considers age and gender differences in the probability and consequences of job mobility; specifically firm exits and promotions in Russia. Russia's labour market should have high rates of job mobility, but we will show using IMF figures that the rate between 2011 and 2015 is on par with the 1980 's. Beyond this, little is known about who is mobile and whether mobility has any impact on wages once the characteristics of movers are controlled for. In other words, we will ask whether job mobility is a sorting mechanism, or whether it has premiums in pay in and of itself. Results show a gender difference in the likelihood of firm exit but not in the likelihood of promotion. When several personal and job characteristics are held constant, young men and women have similar odds of promotion. However, promotions have a positive effect only on the wages of young women; young men's wages are not affected. On the topic of firm exits, when several personal and job characteristics are held constant, exit is more common among young men when compared to young women; this is also true of middle aged men and women. Further, young men see a significant decrease in wages following an exit, while young women are not affected by exit. These results are flipped for middle aged workers; middle aged men see no change in wages following an exit, but middle aged women see significant declines in wages following an exit. Using these results, the article shows that the early stages of a respondent's career are marked by periods of high mobility, which is similar to the experience of young workers in other countries. After this period, mobility becomes increasingly unlikely. Part of this result could stem from the premiums tied to promotion. Results help to understand processes of inequality in wages and conditions that occur due to sorting, and the importance of promotions (internal job changes with the same employer) as 'life chances' which improve earnings in the immediate sense. Gender differences in securing these life chances help to understand wider gender gaps in earnings, which emerge later.
\end{abstract}




\section{Introduction}

Russia's liberalized economy gave workers more employment options and a wider spectrum of potential wages and conditions (IMF 1991; Clarke 2002, 2000; Kozyreva and Sabirianova Peter 2015), at least when compared to the Soviet Union. When countries liberalize in this way, theorists often assume that workers will increase their mobility in order to correct earnings and conditions (Keith and McWilliams 1995, 1997; Cha 2014; Clarke 2002). Such corrections are an important part of job searching and job matching theories of inequality (Schmelzer 2012; Schmelzer and others 2011). Despite these predictions, we will show that Russian job mobility between 2010 and 2015 was on par with the same rate in 1988 Soviet Union (IMF 1991). In a summary of the Soviet economy, the IMF (1991, Table IV.6.5) estimate that the separation rate in manufacturing (a key sector) was approximately 17\%, and that voluntary exits accounted for roughly $45 \%$ of these transfers. Although Russians saw significant labour churn immediately after the reforms of the 1990's, this rate gradually declined and returned to previous levels, with workers remaining in the same job with the same employer (Clarke 2000). We will show that job exits between 2010 and 2015 are roughly on par with the separation rate captured by the IMF. For this reason Russia presents an interesting puzzle for researchers, one where high wage inequality exists parallel to low job mobility.

Russia experienced significant economic change throughout the 1990's, but has moved to a period of (relative) stability during the 2010 decade. The country's employment rate increased from 58 per cent in 2000 to 62 per cent in 2010, and has risen steadily to 65 percent in $2016^{1}$. During this year, the employment rate among men (71 per cent) was higher than it was among women (60 per cent). In terms of economic growth, GDP increased steadily between 2010 and 2014 (roughly 3 per cent per year), before falling roughly 3 per cent in $2015^{2}$. Real wages also increased steadily between 2010 and 2014 (roughly 4 per cent per year) although these also fell in $2015^{3}$. In general, the study focuses on a period of relative stability, with the exception of 2015 .

This article has two aims. First, we will focus on predicting mobility and estimating group differences in who moves and who remains in the same job with the same employer. Do gender differences in Russia's job mobility exist, and do they exist beyond gender differences in occupational sorting and firm tenure? Second, having established these differences, we will consider the effects of job mobility on wages. Does mobility reward workers with higher wages, or is job mobility simply a sorting-mechanism, which leads workers with specific characteristics to higher paid jobs?

We will use the Russia Longitudinal Monitoring Survey (RLMS) as a representative sample of the country's workforce. This approach has two strengths which are relevant to the wider job mobility debate. First, the survey explicitly measures firm exits and promotions which occurred in the last twelve months. Previous authors discussing mobility often operationalise promotions and exits in complex ways (Kalleberg and Mastekaasa 2001; Keith and McWilliams 1995, 1997), but we will avoid this issue by using clear measures of promotion and exit. Second, longitudinal data lets us focus on the effects of mobility on wages, instead of comparing the wages of movers to the wages of non-movers (Cha 2014; Reichelt and Abraham 2017). Since mobility is not a random event, we will remove the influence of unmeasured person-specific characteristics and consider the net gains produced by job mobility.

The article has three findings. First, mobility is most likely in the earliest stages of one's career. For young and middle aged workers, age and firm tenure are negatively correlated with mobility. This is true of both promotions and firm exits and suggests that young workers are especially reliant on job changes to find the right position. Second, there is no difference between young women and young men in terms of promotion after controlling for a range of factors like working time, marital status, and number of children in the home. This is also true of middle-aged workers, who see no gender difference in promotion after we control for similar factors. A gender difference exists in terms of firm exits, with young and middle aged men being more likely to exit a firm when compared to young and middle aged women. Third, there may be no gender difference in the likelihood of promotion, but there is a significant difference in the returns to earnings following a promotion when comparing young men to young women, with young women benefiting from these changes far more than young men. Further we find a gender difference in the effects of firm exit among young men and

\footnotetext{
${ }^{1}$ Russia in Figures 2017 p.92

${ }^{2}$ Russia in Figures 2017 p.38

${ }^{3}$ Russia in Figures 2017 p.37
} 
women, with young women being unaffected by firm exit and young men seeing a significant fall in wages after the change. Regarding middle aged workers, we find few gender differences in the effect of mobility on wages. However, one surprising difference is the negative effect of firm exits on women's earnings in subsequent jobs.

These effects may stem from the overall gender gap in pay. This article proposes that women's wages may suffer from a "sticky floor", where they have a brief window of opportunity to secure higher wages at the start of their careers. Thus for young women, promotions come with a significant effect in terms of wage premiums, whereas for young men, promotions have no significant effect on earnings, given their already higher rate of pay when compared to women. This would also explain why young men see a fall in earnings after a firm exit whereas young women are unaffected by the change. Men who leave a firm have more "distance" to travel in terms of reaching a wage floor, while for women this distance is far shorter. We will illustrate this argument later.

The article is structured as follows. The first section summarises the theoretical literature on job mobility. The second section summarises the empirical findings between age, gender, and job mobility. This section also presents Russia as an important case for studies of job mobility. The third section summarises our data and approach to estimating mobility, and estimating the effects of mobility. Section four presents the results, discusses the findings, and concludes the article.

\section{Review}

\section{Job searching and Job matching}

Studies of job mobility rely on two theoretical approaches, job-searching and job-matching. Both suggest that poor work environments (either from inadequate pay or inadequate conditions) push workers to search for new positions (Kalleberg and Mastekaasa 2001; Gesthuizen and Dagevos 2008; Schmelzer and others 2011). The job searching approach uses the Reservation Wage concept to consider mobility, which is often split in two; reservation wage $x$ and reservation wage $y$. We discuss both in turn.

Wage $x$ is the minimum wage that a worker will accept before leaving unemployment for employment. Wage $y$ (where $x<y$ ) is the minimum wage that a worker will accept before leaving a given position for a new position, either with a new employer or the same employer. If a previously unemployed worker accepts wage $x$ and this wage is below wage $y$ (which is the norm) then she is assumed to continue searching until she finds wage $y$ (Schmelzer 2010; Burdett 1978). If a previously unemployed worker accepts a wage that satisfies both wage $x$ and wage $y$ then she is assumed to continue working until retirement (Schmelzer 2010; Burdett 1978). In this paper we are primarily interested in reservation wage y, given this theory we would expect that changes in position will lead to wage premiums for both men and women.

On the other hand, the job-matching approach is one where workers take time to evaluate whether their skills match and experience matches with their tasks at work. Since work is an experience good, workers must try several jobs before finding a match. Thus the large rates of mobility that workers see in the early stages of their career, is them navigating the labour market, trying individual employers and jobs and comparing their experience with previous experiences (Sørensen 1977; Thurow 1975). This concept is subtly different, and does not consider wages. Instead it considers all aspects of the job and whether a respondent is comfortable with these given her resources. Given this theory we would expect workers to change jobs voluntarily without seeing premiums in wages, because workers are still trying to find a good match between their skills and their general work environment.

How can these theories help us understand age and gender differences in mobility rates? Regarding age, both the job-searching and job-matching approaches agree that worker mobility is prominent among younger workers. However while the job-searching approach sees early mobility as a push for higher wages, the job-matching approach is a push for better job-fit. In the job searching approach, individuals try to secure their reservation wages as they establish themselves in the labour market and gain the experience and networks needed to evaluate new positions. As they gradually close the gap between their given wage and their reservation wage, they become less mobile hence the correlation between age and job mobility (Sørensen 
1977, 1975; Kalleberg and Sørensen 1979). The job-matching approach is slightly different in that it does not expect a wage premium tied to mobility, only that the subjectively evaluated match between a worker and her position should improve following mobility. Given that younger workers know little about the labour market until they experience it first hand, they are expected to move to gather this experience and to make judgement themselves. Hence this approach has a slightly different explanation for the negative correlation between age and mobility.

Regarding gender, these differences are less clear since neither theory explicitly states why men and women would differ. In the job-matching approach it's possible that women have less bargaining power or shorter networks when compared to men, and so are less likely to secure wage $y$ or hear of new opportunities. In terms of the job-matching approach, women (who must often balance both work and care as well as the anticipation of combining work and care in the future) may have several more facets of work which they must consider in order to find a "good match" (Javdani and McGee 2019; Cha 2014).

Elsewhere authors propose that gender differences in mobility (Lazear and Rosen 1990) or reward (Javdani and McGee 2019; Bjerk 2008) stem from statistical discrimination. Specifically, employers will discriminate against women without children, in the early stages of their career in anticipation of family formation (Javdani and McGee 2019; Lazear and Rosen 1990). This discrimination leads to fewer promotions or other job opportunities (employment exits). Employers have no reason to discriminate against women with children, since their labour market participation is not in question. This form of discrimination should not apply to men, given they are unlikely (or perceived as unlikely) to stop working after the birth of their children.

Bjerk (Bjerk 2008) further proposes that groups (in this case men and women) differ in their ability to send "ability signals" at work and at extracurricular activities related to work, hence their lower chances of promotion. This is especially true of women with children (Javdani and McGee 2019). However it is unclear whether this gap applies to mobility outside the firm to new employers.

\section{Gender differences in mobility and its returns}

\section{Gender and mobility}

We now turn to the empirical literature, where we first consider gender differences in mobility (either a quit or a promotion). The findings are generally mixed, even when authors focus on young workers alone. Several authors find a gender difference in promotion and quitting (Javdani and McGee 2019, @blau1981race, @hachen1988gender), and several others report no significant difference in these, when comparing men and women (Cha 2014, @gesthuizen2009job).

In a wide study of US job mobility Hachen (1988) notes that women are particularly immobile in the labour market, being less likely to quit a job, and also less likely to receive a promotion, when compared to men. This finding stands even in highly feminised occupations.

In a more recent paper, Javdani and McGee (2019) find a similar result using a Canadian sample of workers. They note singificant gender difference in the chances of experiencing a promotion, one that cannot be explained by hours worked, overtime, or supervisory position. This gap is also significant for women without children when compared to men without children, which suggests employers are anticipate family formation for these women. Women with children on the other hand, typically see a similar chance of experiencing promotion when compared to men with children, but their earnings growth is slower than that of men with children who experience the change, which seems to suggest that employers are satisfied with these women's low chances of exiting the labour market as suggested by atuhors. Crucially, controlling for supervisory roles, working time, and overtime does not explain the difference in either promotion or earnings growth following a promotion. The finding tied to women without children suggests that women in the earlier stages of their career find it hard to secure promotion, but once this is secured, their earnings typically rise at the same pace as men's. There is thus a potential barrier to promotion at the start of women's careers.

Several authors do not report gender gaps in promotion. Bosquet et al., (2019) explore these differences using a sample of French economists. They find no significant difference in promotion between men and women. 
However, they note that women are significantly less likely to seek out promotion, which suggests they are less likely to participate in job search. This may mean they are better able to secure well matched jobs, or better matched reservation wages. Once models control for pursuit or application of promotion, results between men and women are similar, for this particular occupation.

Elsewhere, Hospido et al., (2019) note the importance of firm level measures and policies when predicting women's mobility likelihood. They also use economists' job history data at the European Central Bank to consider gender differences in promotion. The authors find a gap in favour of men, prior to 2010. After 2010 this difference disappears most likely due to internal efforts to close gender differences and promote diversity. Once again, the authors note that women are significantly less likely to apply for promotion when compared to men, and although there was no difference in the likelihood of promotion between genders after the policy change, this lack of application likely plays a part in earnings differences which are exaccerbated over time.

Authors have also compared gender differences in promotion and quitting. Gesthuizen (2009) at first finds that women in the Netherlands are more likely to exit the firm and more likely to secure promotion when compared to men. However, this difference disappears once Gesthuizen (2009) controls for dissatisfaction with work. This suggests dissatisfaction explains both of difference between men and women in promotion, and the difference between men and women in voluntary quits; in short, women in the Dutch sample are more likely to cite dissatisfaction with conditions, and are also more likely to move, offering some support for the job matching hypothesis.

A key factor in discussions of gender differences in firm exit, is the type of mobility considered. Keith and McWilliam (1995) do not find a gender difference when predicting "economic quits", suggesting that young men and young women are equally likely to leave a firm for a better opportunity with a new employer or firm. However, they find that "family-related quits" are more common among young women when compared to young men. This suggests that previous studies noting a gender difference in mobility, like Blau and Duncan (1981) may over-state gender differences in certain voluntary firm exits or quits. Not all of these changes may be strictly economic quits, as presented by Keith and McWilliam (1995), and some may occur for family reasons or other obligations which may disproportionately fall on women. However, this does not explain the results reported by Hachen (1988) who claims that women are particularly immobile when compared to men.

In general, the literature suggests that gender differences in mobility are uncommon and often may be explained by additional measures, such as the type of job mobility experienced.

\section{Gender and returns to mobility}

We will also consider the literature on gender differences in returns to mobility. Here too, authors have produced mixed findings, although most report no gender difference in the premium tied to firm exits or promotions. Keith and McWilliams $(1999,1997)$ report no such difference, assuming mobility occurs for "economic reasons" and not "family-related" reasons. They do not consider the impact of promotions. Gesthuizen (2009) too finds no significant difference between men and women in subjective premiums tied to mobility within or between firms. Fuller (2008) also considers this difference, finding that early quits during the first five years of one's career yield an equally positive result in the wages of both men and women. She explores this difference further, comparing early career movers with children and finding that both men and women see positive changes in wages after the change. When Fuller (Fuller 2008) substitutes marital status for children a similar result emerges, men and women see similar returns to job mobility regardless of their marital status. In short, results suggest some premium tied to voluntary mobility exists, however, this premium appears equally likely for both men and women. As with gender differences in mobility, this premium applies strictly to economic quits related to the reservation wage.

However, a number of authors do find a gender difference in the effect of changing jobs. Kronberg (2013) is one of the few authors who notes a gender difference in mobility's effect on earnings. She notes that men gain more from a voluntary exit to a new employer when compared to women, although women also see a premium in wages. Crucially, Kronberg (2013) notes that the effect applies only to men and women in "good jobs", characterised as those in high paying occupations with benefits and insurance. In the UK, Lup (2018) reports that women who take a promotion see no change in their subjective satisfaction with work, 
whereas men see an improvement in this measure. Cha (2014) reports a difference between single women and women with children regarding the effect of a quit on earnings. According to Cha (2014) women with children see almost no rewards after the change, compared to women without children who see significant premiums. However, since the study does not consider men, and so it is not possible to comment on gender differences in quit and promotion premiums.

Javdani and McGee (2019. p.219) also find that women experience less wage growth following a promotion, " $a$ woman in Canada needs to be promoted just to experience the same wage growth in a year as a non-promoted man." However, this finding largely depends on whether women have children or not. Women without children see similar earnings growth when compared to men after a promotion. Women with children see slower earnings growth following a promotion, when compared to similar men who experience promotion. They also argue that working hours are a crucial factor in determining promotion and return on promotion, concluding that more flexible forms of work will likely close some of the gender differences in promotion and return on promotion.

In general, it appears that gender differences in the return to mobility are minor, and likely affect specific type of women, such as married women or mothers, rather than young workers more broadly.

\section{Gender and Russia's labour market, as a case}

Most of the papers above rely on US data, and so may not apply to Russia so easily. Clarke (2002) outlines why Russia is a special case, noting the sharp rise in wage differences which occurred throughout the 1990's. These wage differences are particularly important because they exist within occupations, regions, and similar positions, which suggests that every incentive for job mobility exists in Russia and yet the rate is comparably low. Clarke (2000) also notes that despite the high rates of wage inequality and job mobility in the 1990's, job mobility has declined without a corresponding fall in wage differences. He hypothesizes that Russia is a country where "there are significant barriers to labour mobility that are preventing the erosion of these differentials" [in wages]. Again, this large inequality in wages is particularly strange because it occurs within occupations and within regions, suggesting that workers have much to gain from local job mobility, if only in terms of wages and not other factors like housing or access to employer sponsored childcare. Clarke concludes (2000) that personal acquaintances and individual networks are particularly important in securing high wages in the wider labour market, this mechanism has led to a "closing" of the Russian labour market since the 1990's, making Russia a particularly interesting case for study. This is somewhat backed up by Turunen (2004), who finds that during that time, many well educated white collar workers who were based in the public sector, hesitated in taking jobs in the newly formed private sector. Since many of these firms were new or lacked clear career paths, many workers, especially those with high human capital, considered these to be "bad" jobs.

On the topic of gender differences in mobility, Gerber and Mayorova (2006) contradict many of the US and British findings above, reporting that throughout the 1990's women relative to men, had higher rates of layoff and labour market exit, and higher odds of starting in low-quality jobs. Further, they find that women reported lower odds of voluntary job mobility overall, and lower odds of holding good quality jobs. In short, while Russia's transition to a market economy may have improved women's access to jobs, women remain at a disadvantage relative to men, according to the authors (Gerber and Mayorova 2006). In general, the topic of job mobility and its wage premiums has not received much attention in Russia.

\section{Methodology}

We will use five rounds of Russia's Longitudinal Monitoring Survey (Rounds 20-24) as a representative and longitudinal sample of Russia's population (Kozyreva and Sabirianova Peter 2015). This approach covers years 2011 to 2015 and avoids the European Debt Crisis, but partially includes the Russian financial crisis between 2014 and 2015. Using this sample we draw on objective measures of earnings and job mobility for men and women, we also use respondents' age to consider broad age categories for young workers, middle 
Table 1: Total number of waves recorded out of five

\begin{tabular}{rrr}
\hline observations & Total_waves & Proportion \\
\hline 4687 & 1 & 0.11 \\
6302 & 2 & 0.14 \\
8898 & 3 & 0.20 \\
9284 & 4 & 0.21 \\
15205 & 5 & 0.34 \\
\hline
\end{tabular}

aged workers, and older workers. We will consider two estimation techniques for both aims. When predicting group differences in job mobility, we consider multinomial logistic regression. When estimating the effects of mobility on earnings, we will use fixed-effects linear models. We discuss each of these details in the subsections below.

\section{Sample}

The RLMS is a representative and longitudinal study of the Russian population (Kozyreva and Sabirianova Peter 2015; Kozyreva, Kosolapov, and Popkin 2016). Data is collected at the household level annually. The survey contains a rich range of questions on employment and earnings, including measures of job mobility over the last twelve months. It is particularly useful because it captures both internal and external job changes. We will focus on the following sample throughout; observations where respondents are in employment; observations where respondents are not in self-employment, education, or inactivity; and observations where respondents have no missing values for job history or mobility. The final data frame takes the form of a person-year file, which contains $16,100+$ respondents and $44,000+$ observations. The final dataset is also not balanced, in that some respondents have a single observation, while others have several. We summarise this layout below and show that most respondents have multiple observations.

\section{Variables}

This section considers three different sets of variables; job mobility, wages, and a standard set of controls, personal and firm specific. Starting with measures of job mobility, we will rely on three variables within the RLMS dataset. The first asks respondents whether they changed jobs since November of the previous year (IXNEWJOB). Using this measure we can capture the most basic form of mobility, whether respondents remain in the same job with the same employer, whether they changed jobs with their employer, and whether they changed employers. The next measure asks respondents whether they received a promotion since November of the previous year (IXPROMOT), allowing us to separate promotions from other internal moves, such as lateral changes. The final measure asks respondents whether they experienced a lateral move since November of the previous year (IXMOVOA), which allows us to capture lateral changes which occur within the same employer, but which are not promotions. As a result we are left with a four categories of mobility, capturing (1) respondents in the same job with the same employer, (2) respondents who exit the firm, (3) respondents who receive a promotion, and (4) respondents who experience a lateral move within the same firm. One limitation of this measure is that we cannot distinguish between voluntary and involuntary firm exits, although research suggests that voluntary mobility is often the most common type of firm exit (Keith and McWilliams 1995).

Regarding wages, we consider the log of hourly net wages in rubles from the respondent's primary job ${ }^{4}$. If respondents are paid in a different currency they are asked to convert the monthly amount to rubles. We specifically focus on wages from the main job; and ignore other measures like total monthly income

\footnotetext{
${ }^{4}$ we calculate this measure by dividing monthly earnings (IXWAGELM) by weekly working hours (IXPWRKWH, which we multiply by four), and then calculating the log of this measure
} 
(IXINCLMO), this is to capture the reservation wage mentioned above. Income from other sources like returns on savings, or returns on rental properties, do not come about from job searching, and so do not constitute a reservation wage.

Finally, we consider a set of controls for models predicting mobility and models predicting wages. Our main control of interest are gender and age. We will consider groups of young (18-35), middle aged (36-55), and older workers $(55+)$ separately. As mobility is uncommon among older workers, we will focus mostly on younger and middle aged workers throughout the article. Beyond this, authors above mention the importance of human capital and experience; while we cannot measure a respondents full labour market experience directly, we can capture some of this effect using a respondent's age (IXAGE) measured on a linear scale. Further, we note the importance of tenure as a measure of firm specific human capital, or the level of internal labour market experience reported by respondents. We capture this measure using the year the respondent started with their current employer (IXJBSYR), and the current survey year. We also want to capture "pure" mobility effects (Le Grand and Tåhlin 2002), and so we controls for occupational differences (IXILPJB8) in mobility as well as the effects of occupational mobility on wages. Since occupations have multiple values, we simplify this group into High, Medium, and Low EsEC groups (Rose and Harrison 2010), in an effort to control for white, blue, and no collar jobs, and the transition between these jobs. Further, we consider whether respondents hold supervisory positions within the same occupation (IXPRISUB), in an effort to avoid changes in responsibility within the same role. In addition, we will control for changes in marital status (IXMARIST) and the number of children in the home (IXNKIDS) in an effort to anticipate changing social roles which may impact wages. Although the authors above highlight the importance of motherhood and fatherhood when outlining earnings growth and job mobility, we will first focus on the importance of age and gender; considering the interaction of these measures together is beyond the scope of this article but could inform future work on the Russian labour market. Finally, we include two firm level measures, the size of the firm (IXPJEMPS), and whether the government is an owner or partial owner of the enterprise where the respondent works (IXENTGOV). We will only include these firm-level measures into the multinomial logistic regression since these factors rarely change over time. A table of summary statistics is listed below.

\begin{tabular}{lll}
\hline & gender: Male $(\mathrm{N}=20,273)$ & gender: Female $(\mathrm{N}=24,103)$ \\
\hline mob_final & & \\
Same & $14,747(76)$ & $18,452(81)$ \\
Promotion & $848(4)$ & $1,022(5)$ \\
Lateral & $251(1)$ & $276(1)$ \\
Exit & $3,550(18)$ & $2,937(13)$ \\
Unknown & $877 / 20,273(4)$ & $1,416 / 24,103(6)$ \\
wage & 0.00 & 0.00 \\
minimum & $20,000.00(13,000.00$, & $14,000.00(8,000.00$, \\
median (IQR) & $30,000.00)$ & $20,000.00)$ \\
mean (sd) & $23,923.29 \pm 18,978.00$ & $16,694.74 \pm 13,639.20$ \\
maximum & $430,000.00$ & $300,000.00$ \\
Unknown & $1,398 / 20,273(7)$ & $1,954 / 24,103(8)$ \\
gender & & $0(0)$ \\
Male & $20,273(100)$ & $24,103(100)$ \\
Female & $0(0)$ & 15 \\
age & 15 & $39(30.00,50.00)$ \\
minimum & $38(29.00,49.00)$ & $40.39 \pm 12.25$ \\
median (IQR) & $39.34 \pm 12.31$ & 81 \\
mean (sd) & 87 & 0.00 \\
maximum & & $5.00(1.00,11.00)$ \\
tenure & 0.00 & $8.06 \pm 9.36$ \\
minimum & $4.00(1.00,9.00)$ & \\
median (IQR) & $6.47 \pm 8.07$ & \\
mean (sd) & & \\
& &
\end{tabular}




\begin{tabular}{|c|c|c|}
\hline & gender: Male $(\mathrm{N}=20,273)$ & gender: Female $(\mathrm{N}=24,103)$ \\
\hline maximum & 103.00 & 106.00 \\
\hline \multicolumn{3}{|l|}{ super } \\
\hline No & $16,053(79)$ & $19,502(81)$ \\
\hline Yes & $4,180(21)$ & $4,570(19)$ \\
\hline Unknown & $40 / 20,273(0)$ & $31 / 24,103(0)$ \\
\hline \multicolumn{3}{|l|}{ esec_simple } \\
\hline High & $5,502(29)$ & $11,357(50)$ \\
\hline Medium & $1,425(7)$ & $3,759(17)$ \\
\hline Low & $12,200(64)$ & $7,577(33)$ \\
\hline Unknown & $1,146 / 20,273(6)$ & $1,410 / 24,103(6)$ \\
\hline \multicolumn{3}{|l|}{ marr } \\
\hline Never married & $4,523(22)$ & $4,362(18)$ \\
\hline Married & $13,286(66)$ & $12,702(53)$ \\
\hline Separated & $2,364(12)$ & $6,934(29)$ \\
\hline Unknown & $100 / 20,273(0)$ & $105 / 24,103(0)$ \\
\hline \multicolumn{3}{|l|}{ hours } \\
\hline minimum & 2.00 & 1.00 \\
\hline median (IQR) & $40.00(40.00,48.00)$ & $40.00(37.00,45.00)$ \\
\hline mean $(\mathrm{sd})$ & $46.70 \pm 13.72$ & $41.46 \pm 11.47$ \\
\hline maximum & 240.00 & 168.00 \\
\hline \multicolumn{3}{|l|}{ gov } \\
\hline Not government owned & $10,540(61)$ & $9,969(46)$ \\
\hline Government owned or co-owned & $6,714(39)$ & $11,631(54)$ \\
\hline Unknown & $3,019 / 20,273(15)$ & $2,503 / 24,103(10)$ \\
\hline \multicolumn{3}{|l|}{ size } \\
\hline 0-99 & $7,433(63)$ & $12,162(72)$ \\
\hline $100-199$ & $1,215(10)$ & $1,456(9)$ \\
\hline $200+$ & $3,107(26)$ & $3,172(19)$ \\
\hline Unknown & $8,518 / 20,273(42)$ & $7,313 / 24,103(30)$ \\
\hline \multicolumn{3}{|l|}{ kids } \\
\hline No kids & $5,342(26)$ & $4,228(18)$ \\
\hline Kids & $14,918(74)$ & $19,872(82)$ \\
\hline Unknown & $13 / 20,273(0)$ & $3 / 24,103(0)$ \\
\hline \multicolumn{3}{|l|}{ n_kids } \\
\hline minimum & 0.00 & 0.00 \\
\hline median (IQR) & $1.00(0.00,2.00)$ & $1.00(1.00,2.00)$ \\
\hline mean $(\mathrm{sd})$ & $1.24 \pm 1.00$ & $1.33 \pm 0.89$ \\
\hline maximum & 9.00 & 7.00 \\
\hline
\end{tabular}

\section{Estimation}

We will consider two sets of models throughout the article. The first predicts the likelihood of promotion or firm exit, relative to staying in the same job with the same employer. The second estimates the effects of job mobility on the wages of respondents.

On the first point, we will use multinomial logistic regression. Rabe and Hesketh (2008) show how binary logistic regression models can be extended to include more than one outcome.

$$
\operatorname{Pr}\left(y_{i}=1 \mid x_{i}\right)=\frac{1}{1+\exp \left(\beta_{0}^{[2]}+\beta_{1}^{[2]} x_{i}\right)+\exp \left(\beta_{0}^{[3]}+\beta_{1}^{[3]} x_{i}\right)}
$$




$$
\begin{aligned}
& \operatorname{Pr}\left(y_{i}=2 \mid x_{i}\right)=\frac{\exp \left(\beta_{0}^{[2]}+\beta_{1}^{[2]} x_{i}\right)}{1+\exp \left(\beta_{0}^{[2]}+\beta_{1}^{[2]} x_{i}\right)+\exp \left(\beta_{0}^{[3]}+\beta_{1}^{[3]} x_{i}\right)} \\
& \operatorname{Pr}\left(y_{i}=3 \mid x_{i}\right)=\frac{\exp \left(\beta_{0}^{[3]}+\beta_{1}^{[3]} x_{i}\right)}{1+\exp \left(\beta_{0}^{[2]}+\beta_{1}^{[2]} x_{i}\right)+\exp \left(\beta_{0}^{[3]}+\beta_{1}^{[3]} x_{i}\right)}
\end{aligned}
$$

We will rely on an intercept for the two non-referee outcomes $\left(\beta_{0}^{[2]}, \beta_{0}^{[3]}\right)$, and an estimated coefficient for each outcome $\left(\beta_{1}^{[2]}, \beta_{1}^{[3]}\right)$. This model will allow us to consider group differences in mobility events relative to staying in the same job with the same employer.

Next, we will consider linear fixed effects regression, which will control for person-specific unmeasured variables. We are interested mostly in the effects of mobility within individuals, in that we want to know the effect of moving, rather than the difference between movers and non-movers. As mentioned above, our outcome will be the natural log of hourly wages. Since mobility is not a random process personal, time-fixed, error terms of respondents $\left(\alpha_{i}\right)$, things like motivation, upbringing, or self-sufficiency for example, will likely correlate with a person's chance of exiting a firm or taking a promotion. We can remove their influence on mobility using a "within-estimator", by subtracting each terms from its cluster mean (Longhi and Nandi 2014; Rabe-Hesketh and Skrondal 2008; Allison 2009).

$$
\log \left(y_{i t}\right)-\log \left(\overline{y_{i}}\right)=\beta\left(X_{i t}-\overline{X_{i}}\right)+\left(\alpha_{i}-\overline{\alpha_{i}}\right)+\left(u_{i t}-\overline{u_{i}}\right)
$$

This approach models average deviation in wages $\left(\log \left(y_{i t}\right)-\log \left(\bar{y}_{i}\right)\right)$ for individual $i$ at a given time $t$. The model also considers person specific deviations from a set of controls, which include job mobility $\beta\left(X_{i t}-\overline{X_{i}}\right)$. Importantly, this model omits person-specific errors and avoids individual heterogeneity tied to job mobility $\left(\alpha_{i}-\overline{\alpha_{i}}\right)$. The remaining level-2 errors are tied to person-specific differences over time $\left(u_{i t}-\overline{u_{i}}\right)$. 


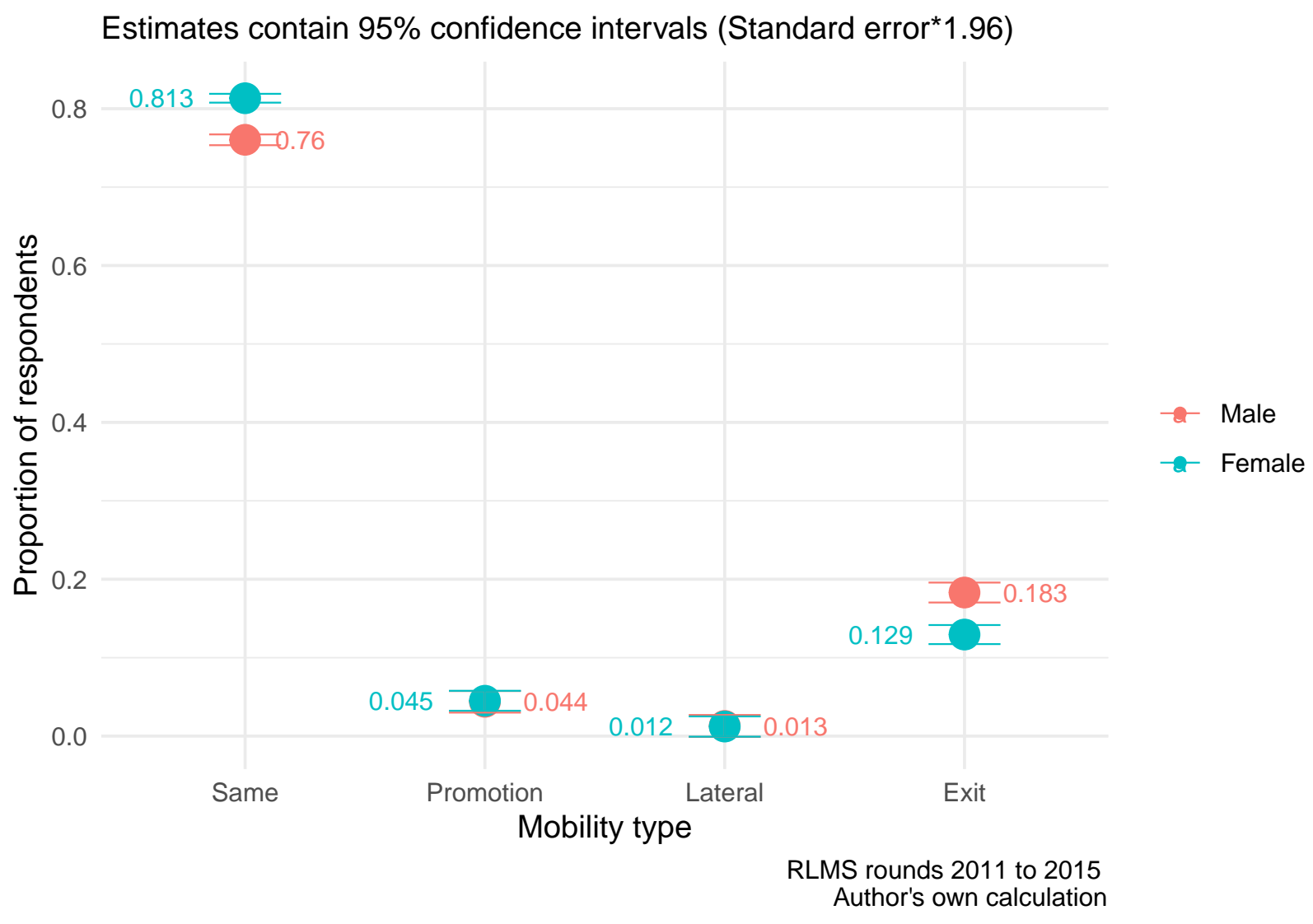

Figure 1: Proportion of respondents citing mobility type by gender

\section{Results}

This section is split into three parts. First, we will discuss summary statistics which look at gender differences in mobility, and gender differences in wages by movers and non-movers. Second, we estimate gender differences in mobility using multinomial logistic regression. Finally, we will explore the effects of mobility on log hourly earnings using fixed-effects linear regression, as mentioned previously.

\section{Descriptive statistics}

Figure 1 considers gender differences in mobility types focusing on observations rather than individuals. We are primarily interested in whether men and women move at a similar rate using observations alone. Overall, respondents are largely immobile although women (0.813) are less mobile when compared to men (0.760). This difference mainly stems from men's higher likelihood of firm exit, when compared to women. Both men and women (0.044) are equally likely to list a promotion in a given year, although promotions are uncommon in general if we consider cross-sectional data alone. Respondents are much more likely to list exiting a firm, with men (0.183) listing more exits than women (0.129). Lateral changes within the firm are the least common mobility type and appear not to have a gender difference. Considering the confidence intervals in Figure 1, it seems gender differences are most prominent in terms of firm exits. Thinking back to the job mobility rate reported for Soviet manufacturing in the 1980's (17\%) (IMF 1991), the rate below is similar despite significant changes to the Russian labour market. Further, there may be evidence of statistical discrimination of women in terms of exits, but not in terms of promotion. 


\section{Estimates contain $95 \%$ confidence intervals (Standard error ${ }^{\star} 1.96$ )}

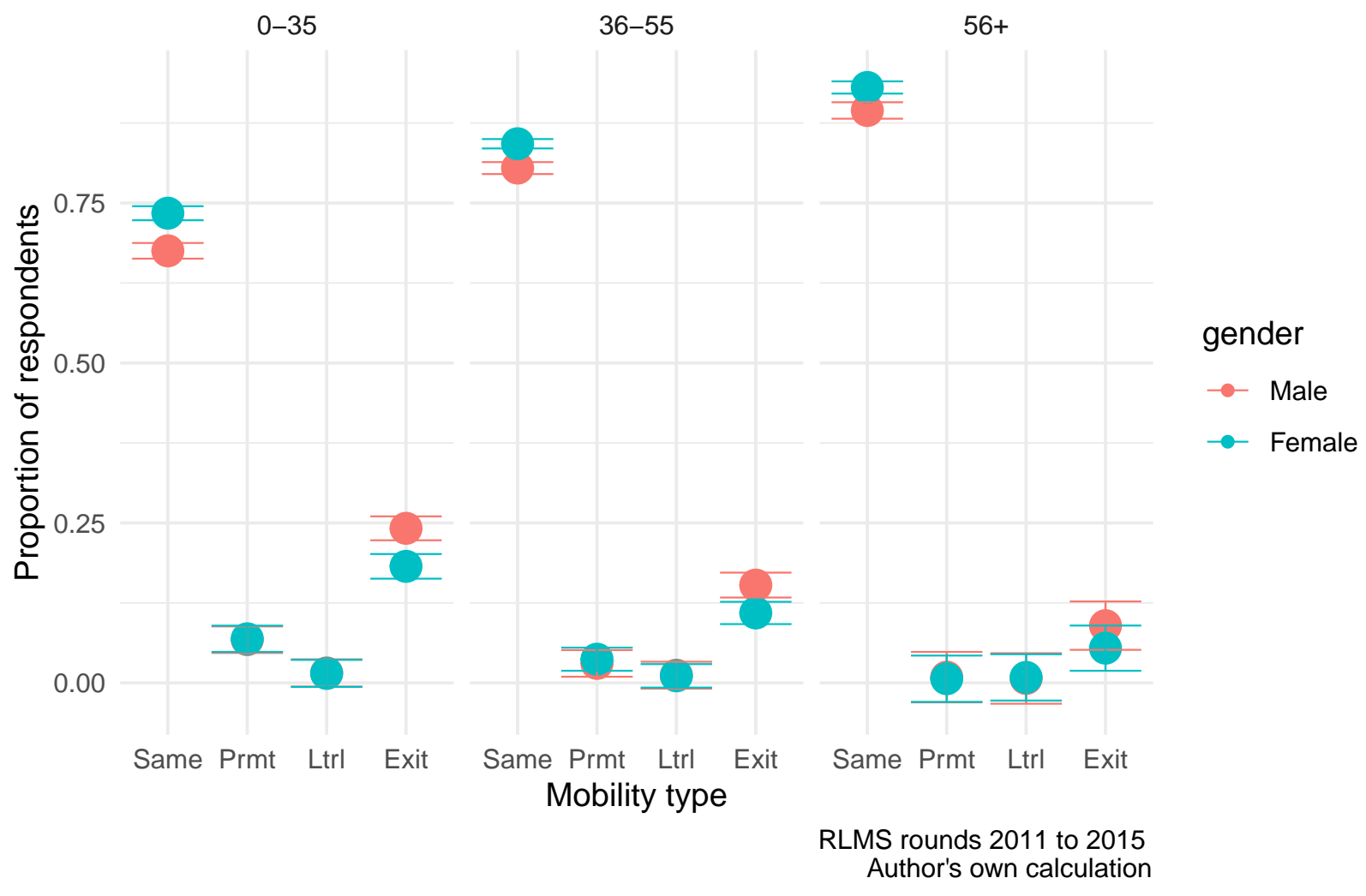

Figure 2: Age and gender differences in mobility

Figure 2 considers the same information, but splits the sample by broad age categories of workers. Younger respondents are more mobile and more likely to list both promotion and firm exit than older groups, who are even less mobile than younger workers. Both of these measures gradually decline as we consider older groups. Notably, the gender difference in firm exits disappears for older groups, but remains for the youngest groups, which suggests that gender differences in mobility emerge in the start of one's career.

Both figures make a key point, there are gender and age effects tied job mobility, with younger workers being more mobile than older workers, and younger men being more mobile than younger women. We now turn to the wage differences between these groups. As mentioned throughout, we will not consider the effect of promotion or exit on wages here. Instead we will consider group differences in average wages, by gender.

Figure 3 captures three important differences. First, there is a gender difference in hourly pay, with men earning more than women in each mobility category. Second, there are differences in pay between mobility groups. For example respondents who experience a promotion in a given year typically cite higher hourly wages than those with the same job and the same employer. Third, there is a pay penalty among respondents who exit a firm, but this penalty is only apparent for men. This may stem from women's pay reaching a "floor", in that pay for women is already low and has little "distance" to travel after an exit, while men's pay sees more "distnace" between their earnings and the floor. Such a difference may stem from the discrimination hypothesis, put forward earlier. Women, especially young women without children are assumed to quit working after they have children, as a result they see less mobility and lower pay overall. Crucially we find that the difference in mobility between men and women stems from a difference in firm exit, however there is also a difference in terms of pay. We consider the age differences in this effect below.

Thinking of differences between age groups in Figure 4, respondents aged 36-55 appear to gain the most from 


\section{Estimates contain 95\% confidence intervals (Standard error ${ }^{*} 1.96$ )}

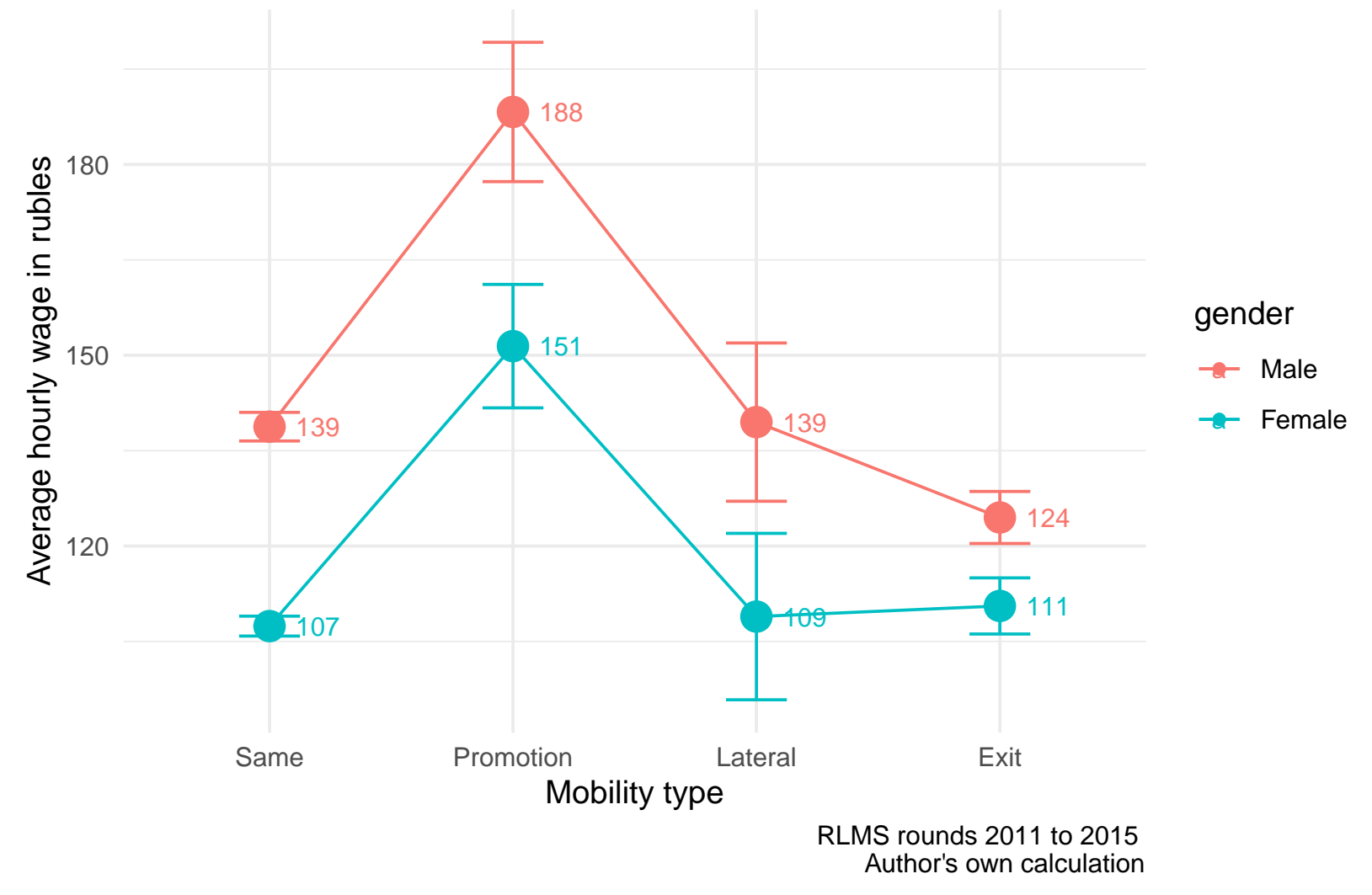

Figure 3: Wage differences between gender and mobility groups 
Estimates contain 95\% confidence intervals (Standard error*1.96)

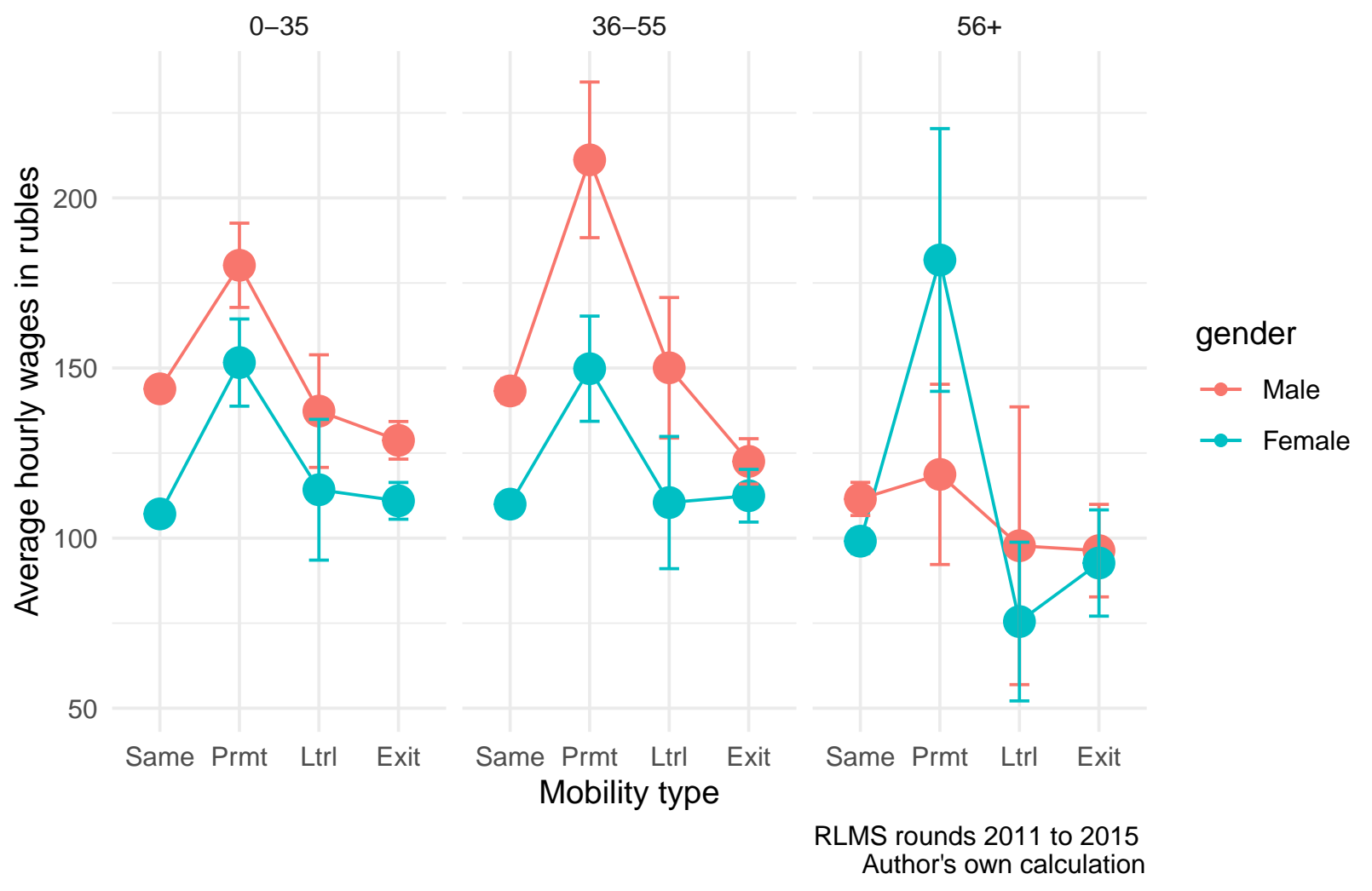

Figure 4: Wage differences between age, gender, and mobility groups 
promotion, especially men. Older groups report the lowest wages and also the lowest return on mobility. Older women appear to make significant gains when citing promotion, however the large confidence intervals suggest this premium is not significantly different from other age groups. These wide confidence intervals likely stem from the fact that mobility is uncommon among older workers. Regardless of this effect, we are primarily interested in the experience of younger and middle aged workers.

Generally, we see a difference between age and gender groups in the likelihood of mobility. We also find that respondents who cite mobility tend to have higher wages in the years when they experience mobility. However, the graphs above only lay out the baseline differences between men and women, without considering differences in experience, firm tenure, and occupational status. The section below turns to these explanations, predicting mobility events using the controls described previously.

So far it appears that genders differ in terms of firm exit but not promotion, and crucially, that there are financial benefits tied to promotion, at least when observing pooled data.

\section{Multinomial logistic regression}

We now consider the effects of other explanatory variables, besides age and gender, in predicting mobility differences. The multinomial logistic regression considers the controls discussed above, as well as gender and age, these are listed in Table 2 .

We discuss the main findings in turn, focusing on one mobility outcome at a time. Regarding promotions, we first look at models for respondents aged 18-35. There is no significant gender difference between young men and women when it comes to promotion, who both have similar odds of experiencing this change. This difference remains even when we control for differences in age, firm tenure, supervisory position, the occupation of respondents, their marital status, their normal hours of work, the sector and size of the firm where they work, and the number of children in the home.

Beyond this, the controls have their own impact on promotions. Younger respondents are more likely to receive a promotion than older respondents, as are respondents with less firm experience compared to respondents with more firm experience. Respondents in supervisor positions are also more likely to cite a promotion when compared to respondents without a supervisor position. Regarding occupations, those in the low occupational group cite lower odds of experiencing a promotion, when compared to the upper occupational group. However there is no significant difference between the middle ESEC group, and the Higher ESEC group. Regarding weekly working time, we find that respondents who work longer hours are not more likely to experience a promotion, when compared to respondents who work fewer hours, which is surpising since it suggests that part-time workers have an equal chance of securing promotion when comapred to those who work longer hours. It's possible that there is little variation in working hours for the 18-35 age group. Finally, there is a difference between respondents in smaller firms (1-99 employees) and larger firms (200+ employees). Those in large firms are more likely to experience a promotion when compared to those in small firms, most likely because of greater opportunities and career ladders.

In general, promotions occur most often among young respondents with supervisory positions, in higher occupations. These results suggest that the early stages of one's career are crucial to establishing chance of promotion, and that young women and young men have roughly similar chances of experiencing the event, even when controlling for compositional and firm level differences between men and women. These findings reflect Figure 1 and Figure 2 outlined above, which show a similar rate of promotions for men and women.

We now turn to respondents aged 36-55. Here too, we find no gender difference in the likelihood of promotion. However, the remaining controls once again have an impact. Younger respondents (within the age group) are again most likely to cite a promotion, as are respondents with less tenure than more established workers. Those who are in supervisor positions are more likely to experience promotion when compared to respondents without a supervisory position. There are also significant differences between occupational groups in terms of promotion, with low ESEC occupational groups being significantly less likely to experience promotion when compared to those in higher groups. Lastly, there are firm level differences in workers' chances of citing a promotion. Once again, those in large firms are more likely to experience a promotion when compared to 
Table 3: Multinomial logistic regression models, split by age

\begin{tabular}{|c|c|c|c|c|c|c|c|c|}
\hline \multirow[b]{2}{*}{ term } & \multicolumn{4}{|c|}{ Age $18-35$} & \multicolumn{4}{|c|}{ Age $36-55$} \\
\hline & estimate & std.error & p.value & signif & estimate & std.error & p.value & signif \\
\hline \multicolumn{9}{|l|}{ Promotion } \\
\hline (Intercept) & 0.586 & 0.376 & 0.155 & & 0.404 & 0.474 & 0.056 & . \\
\hline genderFemale & 0.905 & 0.087 & 0.250 & & 1.062 & 0.115 & 0.601 & \\
\hline age & 0.936 & 0.013 & 0.000 & $* * *$ & 0.944 & 0.009 & 0.000 & $* * *$ \\
\hline tenure & 0.949 & 0.014 & 0.000 & $* * *$ & 0.968 & 0.007 & 0.000 & $* * *$ \\
\hline factor(super)Yes & 3.332 & 0.095 & 0.000 & $* * *$ & 2.807 & 0.118 & 0.000 & $* * *$ \\
\hline factor(esec_simple)Medium & 0.967 & 0.115 & 0.767 & & 0.886 & 0.163 & 0.458 & \\
\hline factor(esec_simple)Low & 0.344 & 0.131 & 0.000 & $* * *$ & 0.288 & 0.183 & 0.000 & $* * *$ \\
\hline factor(marr)Married & 0.954 & 0.104 & 0.653 & & 0.897 & 0.195 & 0.577 & \\
\hline factor(marr)Separated & 1.020 & 0.161 & 0.901 & & 1.042 & 0.204 & 0.841 & \\
\hline hours & 1.005 & 0.004 & 0.141 & & 1.006 & 0.005 & 0.195 & \\
\hline factor(size)100-199 & 1.253 & 0.136 & 0.095 & . & 1.287 & 0.159 & 0.112 & \\
\hline factor(size) $200+$ & 1.668 & 0.093 & 0.000 & $* * *$ & 1.625 & 0.113 & 0.000 & $* * *$ \\
\hline factor(gov)Government owned or co-owned & 1.080 & 0.086 & 0.366 & & 1.291 & 0.107 & 0.017 & $*$ \\
\hline n_kids & 0.993 & 0.065 & 0.910 & & 1.015 & 0.065 & 0.814 & \\
\hline \multicolumn{9}{|l|}{ Lateral change } \\
\hline (Intercept) & 0.019 & 0.749 & 0.000 & $* * *$ & 0.024 & 0.805 & 0.000 & $* * *$ \\
\hline genderFemale & 0.902 & 0.182 & 0.571 & & 0.848 & 0.187 & 0.380 & \\
\hline age & 0.985 & 0.025 & 0.552 & & 0.985 & 0.014 & 0.303 & \\
\hline tenure & 0.930 & 0.028 & 0.010 & $*$ & 0.977 & 0.011 & 0.033 & $*$ \\
\hline factor(super)Yes & 0.958 & 0.252 & 0.864 & & 0.909 & 0.244 & 0.697 & \\
\hline factor(esec_simple)Medium & 1.386 & 0.238 & 0.171 & & 1.471 & 0.263 & 0.141 & \\
\hline factor(esec_simple)Low & 1.075 & 0.213 & 0.734 & & 1.077 & 0.226 & 0.743 & \\
\hline factor(marr)Married & 1.453 & 0.212 & 0.079 & . & 1.249 & 0.386 & 0.565 & \\
\hline factor(marr)Separated & 1.298 & 0.333 & 0.434 & & 1.614 & 0.395 & 0.225 & \\
\hline hours & 1.006 & 0.007 & 0.366 & & 0.993 & 0.008 & 0.382 & \\
\hline factor(size)100-199 & 1.781 & 0.257 & 0.025 & $*$ & 1.288 & 0.293 & 0.388 & \\
\hline factor(size) $200+$ & 2.392 & 0.180 & 0.000 & $* * *$ & 2.319 & 0.178 & 0.000 & $* * *$ \\
\hline factor(gov)Government owned or co-owned & 1.652 & 0.169 & 0.003 & $* *$ & 1.238 & 0.174 & 0.220 & \\
\hline n_kids & 0.824 & 0.131 & 0.137 & & 1.057 & 0.103 & 0.588 & \\
\hline \multicolumn{9}{|l|}{ Exit } \\
\hline (Intercept) & 4.234 & 0.335 & 0.000 & $* * *$ & 2.635 & 0.351 & 0.006 & $* *$ \\
\hline genderFemale & 0.769 & 0.085 & 0.002 & $* *$ & 0.887 & 0.084 & 0.153 & \\
\hline age & 1.001 & 0.011 & 0.900 & & 0.992 & 0.007 & 0.252 & \\
\hline tenure & 0.111 & 0.058 & 0.000 & $* * *$ & 0.344 & 0.034 & 0.000 & $* * *$ \\
\hline factor(super)Yes & 1.082 & 0.124 & 0.526 & & 0.829 & 0.124 & 0.132 & \\
\hline factor(esec_simple)Medium & 1.157 & 0.118 & 0.214 & & 1.031 & 0.138 & 0.823 & \\
\hline factor(esec_simple)Low & 0.867 & 0.104 & 0.170 & & 0.890 & 0.110 & 0.287 & \\
\hline factor(marr)Married & 0.925 & 0.099 & 0.426 & & 1.190 & 0.154 & 0.258 & \\
\hline factor(marr)Separated & 1.055 & 0.149 & 0.722 & & 1.327 & 0.159 & 0.075 & . \\
\hline hours & 1.004 & 0.003 & 0.230 & & 1.002 & 0.003 & 0.533 & \\
\hline factor(size)100-199 & 0.857 & 0.149 & 0.303 & & 0.873 & 0.141 & 0.334 & \\
\hline factor(size) $200+$ & 1.078 & 0.105 & 0.476 & & 0.992 & 0.109 & 0.940 & \\
\hline factor(gov)Government owned or co-owned & 0.701 & 0.091 & 0.000 & $* * *$ & 0.775 & 0.085 & 0.003 & $* *$ \\
\hline n_kids & 1.109 & 0.062 & 0.094 & . & 0.963 & 0.048 & 0.434 & \\
\hline
\end{tabular}

${ }^{1}$ RLMS rounds 20-25. Models consider two separate age groups

$2 * * * \mathrm{p}<0.001, * * \mathrm{p}<0.01, * \mathrm{p}<0.05, . \mathrm{p}<0.1$ 
those in smaller firms, and those in government owned firms or organisations are more likely to experience promotion, when compared to those in strictly private firms. This latter effect could stem from more narrowly defined jobs in the government sector, compared to the private sector.

We now consider lateral changes within the firm, focusing on younger respondents first. We find no gender difference between men and women regarding their odds of experiencing lateral change. Respondents with higher firm tenure are less likely to experience lateral mobility when compared to respondents with lower tenure. The remaining person specific controls are insignificant, but several firm-level measures report significant results. Regarding firm size, workers in larger firms are more likely to experience lateral change, when compared to workers in smaller forms. Further, workers in government owner firms and organisations are significantly more likely to report lateral changes, possibly due to similar roles in new departments, given that models control for occupational status. There are no other significant effects in the model for younger respondents.

Considering workers aged 36-55, the majority of measures are insignificant which is due to the fact that lateral job mobility is uncommon overall and especially uncommon for this age group. Results suggest that higher tenure decreases the chance of citing a lateral change, which emerges for most other groups of respondents. Results also suggest that working in an organisation with over 200 workers increases a respondent's chances of citing a lateral change. This finding simply reflects the higher number of positions within such firms.

Finally, we will focus on respondents who exit a firm. Starting with younger respondents (aged 18-35), we find a gender difference in firm exits. Women are less likely to cite an exit (0.769) when compared to men (1.0). This effect remains even when we control for age, firm level tenure, supervisory positions, occupational differences, marital status, weekly working hours, the size and ownership of the firm, and the number of children in the home. Further, some of the listed controls have their own impact on exit. The age of respondents has no effect on exit, although we only consider a brief range of age. Firm tenure has an impact on exit but this is an artifact in the data, since respondents who exit a firm in the last 12 months will also have low tenure. Government ownership appears to decrease the odds of a worker citing exit, compared to firms that are privately owned; further the number of children in the home appears to have no impact on a respondent's likelihood of quitting. Given the literature review we would expect some interaction between this measure and the gender measure. However, this is beyond the scope of our current study. The remaining measures have no effect on predicting firm exit. For example respondents with and without a supervisory position are equally likely to exit a firm, as are respondents in High, Medium, and Low group occupations.

Considering respondents who are aged 36-55, we find slightly different estimates with fewer significant measures. Again, this is because job mobility for this group is less common than for younger respondents. Women are no longer less likely to cite firm exit when compared to men. Tenure is again a significant measure, but as we noted previously, this is an artifact in the data. The only other significant measure is government ownership of the firm, which again shows lower odds of exit, possibly due to stronger job protection rules and better job-matching.

We note two important results from the models above. First, mobility is most prominent and most common in the earliest stages of one's career, with younger respondents being more likely to cite a change than older respondents. This is especially true when the outcome is a promotion, where both age and tenure are negatively correlated with promotion for both young and middle aged workers. We would argue that once respondents secure a good position, they hold on to it by limiting mobility as much as possible. This is reflected in the coefficient for age, which shows lower odds of changing jobs among older respondents compared to younger respondents. Second, young women are less likely to exit a firm when compared to young men, and this difference cannot be explained by compositional or firm level measures. Even after controlling for these differences young women (but not middle aged women) are still less likely to leave a firm, when compared to men.

These findings contradict a number of previous authors, both those writing about Russia and those writing about other countries. Javdani and McGee (Javdani and McGee 2019) note that women without children report lower chacnes of promotion when comapred to men without children, we do not find a similar result, although we control for number of children in the home. Blau and Duncan (1981) reported a gender difference in exit, with young women being more likely to exit when compared to young men. We find the opposite, 
Table 4: Linear fixed-effects models for younger workers, split by gender

\begin{tabular}{|c|c|c|c|c|c|c|c|c|}
\hline \multirow[b]{2}{*}{ term } & \multicolumn{4}{|c|}{ Male Results (aged 18-35) } & \multicolumn{4}{|c|}{ Female results (aged 18-35) } \\
\hline & estimate & std.error & p.value & signif & estimate & std.error & p.value & signif \\
\hline mob_finalPromotion & -0.002 & 0.036 & 0.954 & & 0.120 & 0.041 & 0.003 & $* *$ \\
\hline mob_finalLateral & -0.039 & 0.064 & 0.545 & & 0.131 & 0.087 & 0.132 & \\
\hline mob_finalExit & -0.058 & 0.027 & 0.030 & $*$ & 0.028 & 0.033 & 0.390 & \\
\hline age & 0.113 & 0.007 & 0.000 & $* * *$ & 0.158 & 0.009 & 0.000 & $* * *$ \\
\hline tenure & -0.005 & 0.005 & 0.257 & & -0.011 & 0.006 & 0.066 & . \\
\hline superYes & 0.100 & 0.040 & 0.013 & * & 0.014 & 0.042 & 0.737 & \\
\hline factor(esec_simple)Medium & 0.043 & 0.042 & 0.303 & & 0.043 & 0.037 & 0.246 & \\
\hline factor(esec_simple)Low & 0.020 & 0.038 & 0.600 & & 0.005 & 0.050 & 0.924 & \\
\hline factor(marr)Married & 0.127 & 0.049 & 0.009 & ** & -0.128 & 0.064 & 0.044 & * \\
\hline factor(marr)Separated & 0.023 & 0.074 & 0.755 & & -0.089 & 0.082 & 0.275 & \\
\hline firm_size & 0.000 & 0.000 & 0.378 & & 0.000 & 0.000 & 0.175 & \\
\hline n_kids & -0.059 & 0.029 & 0.043 & $*$ & -0.461 & 0.049 & 0.000 & $* * *$ \\
\hline
\end{tabular}

${ }^{1}$ RLMS rounds 20-25. Models consider gender separately

$2 * * * \mathrm{p}<0.001,{ }^{* *} \mathrm{p}<0.01,{ }^{*} \mathrm{p}<0.05, . \mathrm{p}<0.1$

noting that young women are less likely to leave a firm. Other authors reported no difference between young men and women (Hachen Jr 1988; Gesthuizen 2009; Keith and McWilliams 1995). Our results do not confirm this, at least in the case of Russia. However, Gerber and Mayorova (2006) use Russian data and report that women experience more layoffs and less "voluntary" job mobility when compared to men. We find instead that women are overall much less mobile when compared to men, although the labour market context in Russia has changed dramatically since the 1990's. Our results do not support the discrimination hypothesis for promotions, although there may be some evidence of discrimination in securing positions with new employers.

Our findings do reflect those of Hospido (2019) and Bosquet et al. (2019) who find no relationship between gender and promotion, assuming that application for promotion is controlled. We do not have such a measure in the dataset, but report a roughly similar relationship, in that men and women who are employed, report roughly similar rates of promotion.

\section{Fixed effects estimation}

Having established the major age and gender differences between quits and promotions, we now turn to their effects on earnings. As mentioned we consider linear fixed-effects estimation throughout. We start by considering respondents aged between 18-35, before considering respondents aged 36-55. We discuss the results for men and women separately since gender is a time-invariant variable, and so cannot be controlled for.

Table 4 focuses on respondents aged 18-35, and the results are separated by gender. Throughout we are searching for gender differences in the return on mobility (Promotions, lateral changes, and firm exits). Young men who experience a promotion report no change in monthly wages, which suggests that any benefits tied to promotion can be explained by person specific characteristics of movers.

Lateral changes have a negative but statistically insignificant effect on earnings, suggesting that workers are able to recreate their earnings after a lateral change within the firm. Firm exits appear to have a negative effect on earnings, suggesting that instance where workers leave a firm for a new employer result in lower earnings (over 5\%). This finding runs contradictory to the reservation wage hypothesis, and could reflect a mix of voluntary and involuntary changes to a new employer. The effects remain even when we control for changes in age, tenure, supervisory position, occupational group, marital status, and firm size.

Beyond this, the listed controls have their own impact on earnings. Male respondents see a strong positive 
effect of ageing on earnings, but an insignificant effect of job tenure on earnings. This tenure effect and age effect are likely correlated given Russia's low rates of job mobility, which would explain why general labour market experience is significant but tenure or firm experience is not. There is also a relationship between moving to a supervisory position from a non-supervisory position, suggesting that respondents who become supervisors see a positive change in earnings after the change even when their occupation or initial position has not changed. Further, controlling for occupational change has no effect on earnings, which is a strange result, but may reflect the fact that occupational mobility is uncommon among young workers (aged 18-35). Finally there is a positive effect marriage and earnings. This suggests that respondents who move from being unmarried to married are able to secure a minor premium after the change. Such a result is common in sociological studies of the labour market, and may reflect a signalling-effect where married respondents are perceived as more efficient or more trust-worthy when compared to unmarried workers with similar skills. Importantly, this difference increases the worker's value of work, in the it affects their hourly wage in rubles. Finally, there is a minor negative effect of children on earnings, in that having more children is associated with a fall in hourly earnings of roughly 5 per cent for men.

We will compare these results to those of women aged 18-35 which are somewhat different. The first significant difference is that young women see a large and significant increase in wages following a promotion, seeing roughly a 12 per cent increase in wages after the change. Women who move laterally within the firm see a 13 per cent increase in pay, but the effect is not significant at the 0.5 level. Lastly, women who exit the firm for a new employer report a 2 per cent rise in pay, but this effect is also insignificant. These findings suggest that promotions, within the firm or with the same employer, are particularly important for young women, who in the early stages of their career must quickly establish themselves. These results do not emerge for men. Again, this result is significant even when we control for women's changes in age, tenure, supervisory position, occupational group, marital status, and number of children in the home; many of which are related to job mobility. Many of these controls have their own effects on monthly wages. First, age has a positive and significant effect on women's earnings. This effect is similar in size to that of men's age on earnings. However, tenure has a negative but insignificant effect on women's earnings, at elast at the 0.5 level. This offers some support for the idea that mobility is crucial to women's earnings in the early stages of their careers, since women who remain in the same job with the same employer may see a gradual fall in earnings over time, even if their working hours and occupation remain roughly the same. However, the decline is only significant at the 0.1 level.

Strangely, there is no premium tied to moving to a supervisory role, which emerged for men. Further, the marriage premium that we noted for men, is now a strong and significant penalty for young women, even when we consider hourly wages as an outcome. This result could also reflect the signalling-theory hypothesis, where married women are misperceived as less efficient, compared to unmarried women. This effect moves in a strikingly different direction for women when compared to men and could reflect the statistical discrimination noted previously where employers anticipate a dropping out of the labour force shortly after family formation. This result is further confirmed by the presence of children in the home, highlighting a sharp drop in hourly earnings after the arrival of children. Here women see a significant fall in earnings for each child in the household.

There are two important results in Table 2. First, the gender difference in the effect of mobility, where women are rewarded for promotion while men are penalized for exit. These results likely stem from the sharp differences in earnings between men and women noted in Figure 3 and Figure 4. Women's earnings are at a floor, and so promotion yield large and significant returns as they are using this mobility to leave that floor. Parallel to this, firm exit has no positive or negative effect, most likely because the "distance" between women's wages and the floor is low. This distance is not low for men, and so young men who exit the firm early see a sudden fall in earnings, at least in the short term, because there is more "distance" between their earnings and the floor. Second, is the negative effect of children and marital status on earnings.

This finding suggests that there is some reaction among employers after women get married and have children, and that early promotion may be one way of avoiding this. We now turn to the results for middle aged, more established, workers.

Starting with men, we note that the effect of promotion remains insignificant, as does the effect of lateral 
Table 5: Linear fixed-effects models for middle-aged workers, split by gender

\begin{tabular}{|c|c|c|c|c|c|c|c|c|}
\hline \multirow[b]{2}{*}{ term } & \multicolumn{4}{|c|}{ Male Results (aged 36-55) } & \multicolumn{4}{|c|}{ Female results (aged 36-55) } \\
\hline & estimate & std.error & p.value & signif & estimate & std.error & p.value & signif \\
\hline mob_finalPromotion & 0.042 & 0.045 & 0.358 & & 0.055 & 0.028 & 0.052 & . \\
\hline mob_finalLateral & 0.052 & 0.063 & 0.411 & & -0.024 & 0.049 & 0.627 & \\
\hline mob_finalExit & -0.002 & 0.028 & 0.942 & & -0.062 & 0.022 & 0.004 & $* *$ \\
\hline age & 0.080 & 0.005 & 0.000 & $* * *$ & 0.099 & 0.004 & 0.000 & $* * *$ \\
\hline tenure & 0.002 & 0.002 & 0.330 & & -0.001 & 0.001 & 0.591 & \\
\hline superYes & 0.086 & 0.040 & 0.032 & * & 0.068 & 0.024 & 0.005 & $* *$ \\
\hline factor(esec_simple)Medium & -0.069 & 0.045 & 0.121 & & 0.008 & 0.025 & 0.751 & \\
\hline factor(esec simple)Low & -0.013 & 0.035 & 0.718 & & 0.030 & 0.031 & 0.341 & \\
\hline factor(marr) Married & -0.021 & 0.084 & 0.807 & & 0.156 & 0.070 & 0.025 & $*$ \\
\hline factor(marr)Separated & -0.054 & 0.087 & 0.533 & & 0.175 & 0.063 & 0.005 & $* *$ \\
\hline firm_size & 0.000 & 0.000 & 0.668 & & 0.000 & 0.000 & 0.756 & \\
\hline n_kids & 0.026 & 0.029 & 0.362 & & -0.061 & 0.034 & 0.069 & . \\
\hline
\end{tabular}

${ }^{1}$ RLMS rounds 20-25. Models consider gender separately

$2 * * * \mathrm{p}<0.001,{ }^{* *} \mathrm{p}<0.01,{ }^{*} \mathrm{p}<0.05, . \mathrm{p}<0.1$

change, and firm exit. Thus middle aged men are able to recreate their working environments with new and existing employers, relying instead on their general labour market experience. This result could stem from the fact that the category contains a mix of voluntary and involuntary exits, or it could stem from the fact that all premiums are explained by the person-specific errors, mentioned above.

We also note that age has a significant but weaker effect, and that tenure has no effect on earnings. This also likely reflects the fact that middle aged workers are in more established positions. As before, moving between supervisory positions has an effect on earnings, with respondents in supervisory roles losing earnings when transitioning to non-supervisory roles, and respondents in non-supervisory roles gaining when transferring to supervisory roles. The previous marriage premium, and the child penalty have also disappeared, also perhaps reflecting the fact that older respondents are more established in the labour market.

The results for middle aged women are rather similar although some differences are worth noting. Women who experience a promotion report an increase in pay of roughly 5 per cent, however this effect is not significant at the 0.5 level. The previous premium of up to 15 per cent is no longer appearing, most likely because middle aged women who receive promotions are part of the core workforce or the primary labour market. The results for lateral changes are insignificant, suggesting women who make these transitions are able to recreate their earnings, holding all other factors constant. The results for firm exits are significant but negative, suggesting that women who leave a firm pay a penalty of up to 5 per cent in terms of earnings in subsequent jobs. This result does not emerge for men. It's possible that women in Russia are particularly reliant on the firm for wage growth and career progression, and once younger workers have proven their worth in the early stages of their career they try to remain with the same employer for as long as possible. Finding a new employer may contain a penalty in that middle aged women must again prove their efficiency. We also see a significant and positive effect tied to age, which suggests that women see premiums in earnings as they gain more human capital or experience at work. This effect does not emerge for firm tenure, possibly due to issues of colliniarity. Women who move to supervisory roles see a premium in wages after the change, reversing the gap in this effect among younger women. The previous penalties tied to amrriage and children are no longer present, in fact middle aged women who become married experience an increase hourly earnings after the change.

In general, middle aged women do not receive a premium tied to promotion, but face a penalty in exit that men are able to avoid. This penalty is likely the reason why women report lower odds of firm exit in Figure 1 and Figure 2. However, we note that young men see a similarly sized penalty in earnings after a firm exit, and they routinely cite higher rates of firm exit. It's possible that they are better able to recover from these penalties over the long term. 


\section{Conclusion}

In general we will make three broad conclusions from our analysis. First, our results suggest that promotions in themselves have mixed effects on earnings; but they are especially crucial for young women. This result does not emerge in other studies listed above (Gesthuizen 2009; Lup 2018), possibly pointing to Russia as a unique case. Second, in a further split from other authors, we find that firm exits rarely have a significant effect on earnings (Keith and McWilliams 1999, 1997; Fuller 2008; Cha 2014). Where they do have an effect on earnings, this effect is mostly negative. This result could stem from three issues. First, the category for firm exits contains more involuntary mobility (like layoffs, dismissals, and redundancies) than voluntary mobility (like new opportunities and new jobs with new firms or employers). Second, if the above is not the case, the positive effects of firm exits are explained fully by the type of person moving, which we cancel out of our models using a "within" estimator. Third, the negative effects are short term, and not indicative of long term changes which may occur with a new employer. Finally, our results report a gender difference in this penalty, with young men experiencing the loss but not young men; elsewhere we find a second gender difference in the effects of firm exits, with middle aged women citing a penalty after the change, but not middle aged men.

Our results suggest that gender differences likely stem from access to mobility in the early stages of one's career. While we find no difference in access to life chances like promotion, these life-chances differ in what they mean for the wages of men and women. Further research should explore the importance of occupational mobility which occurs between men and women, and the interaction between gender and family roles like motherhood and fatherhood. Throughout our analysis, we find that non-market roles (parenthood and marriage) as described by Bjerk (Bjerk 2008) impact young respondents much more than older respondents. 


\section{References}

Allison, Paul D. 2009. Fixed Effects Regression Models. Vol. 160. SAGE publications.

Bjerk, David. 2008. "Glass Ceilings or Sticky Floors? Statistical Discrimination in a Dynamic Model of Hiring and Promotion." The Economic Journal 118 (530): 961-82.

Blau, Francine D, and Lawrence M Kahn. 1981. "Race and Sex Differences in Quits by Young Workers." ILR Review 34 (4): 563-77.

Bosquet, Clément, Pierre-Philippe Combes, and Cecilia Garcia-Peñalosa. 2019. "Gender and Promotions: Evidence from Academic Economists in France." The Scandinavian Journal of Economics 121 (3): 1020-53.

Burdett, Kenneth. 1978. "A Theory of Employee Job Search and Quit Rates." The American Economic Review 68 (1): 212-20.

Cha, Youngjoo. 2014. "Job Mobility and the Great Recession: Wage Consequences by Gender and Parenthood." Sociological Science 1: 159.

Clarke, Simon. 2000. "The Closure of the Russian Labour Market." European Societies 2 (4): 483-504.

. 2002. "Market and Institutional Determinants of Wage Differentiation in Russia." ILR Review 55 (4): $628-48$.

Fuller, Sylvia. 2008. "Job Mobility and Wage Trajectories for Men and Women in the United States." American Sociological Review 73 (1): 158-83.

Gerber, Theodore P, and Olga Mayorova. 2006. "Dynamic Gender Differences in a Post-Socialist Labor Market: Russia, 1991-1997." Social Forces 84 (4): 2047-75.

Gesthuizen, Maurice. 2009. "Job Characteristics and Voluntary Mobility in the Netherlands." International Journal of Manpower.

Gesthuizen, Maurice, and Jaco Dagevos. 2008. "Mismatching of Persons and Jobs in the Netherlands: Consequences for the Returns to Mobility." Work, Employment and Society 22 (3): 485-506.

Hachen Jr, David S. 1988. "Gender Differences in Job Mobility Rates in the United States." Social Science Research 17 (2): 93-116.

Hospido, Laura, Luc Laeven, and Ana Lamo. 2019. "The Gender Promotion Gap: Evidence from Central Banking."

IMF. 1991. "A Study of the Soviet Economy." OECD 3 volumes.

Javdani, Mohsen, and Andrew McGee. 2019. "Moving up or Falling Behind? Gender, Promotions, and Wages in Canada." Industrial Relations: A Journal of Economy and Society 58 (2): 189-228.

Kalleberg, Arne L, and Arne Mastekaasa. 2001. "Satisfied Movers, Committed Stayers: The Impact of Job Mobility on Work Attitudes in Norway." Work and Occupations 28 (2): 183-209.

Kalleberg, Arne L, and Aage B Sørensen. 1979. "The Sociology of Labor Markets." Annual Review of Sociology 5 (1): 351-79.

Keith, Kristen, and Abagail McWilliams. 1995. "The Wage Effects of Cumulative Job Mobility." ILR Review 49 (1): 121-37.

. 1997. "Job Mobility and Gender-Based Wage Growth Differentials." Economic Inquiry 35 (2): 320-33.

. 1999. "The Returns to Mobility and Job Search by Gender." ILR Review 52 (3): 460-77.

Kozyreva, Polina, Mikhail Kosolapov, and Barry M Popkin. 2016. "Data Resource Profile: The Russia Longitudinal Monitoring Survey - Higher School of Economics (Rlms-Hse) Phase Ii: Monitoring the Economic and Health Situation in Russia, 1994-2013." International Journal of Epidemiology 45 (2): 395-401. 
Kozyreva, Polina, and Klara Sabirianova Peter. 2015. "Economic Change in Russia: Twenty Years of the Russian Longitudinal Monitoring Survey." Economics of Transition 23 (2): 293-98.

Kronberg, Anne-Kathrin. 2013. "Stay or Leave? Externalization of Job Mobility and the Effect on the Us Gender Earnings Gap, 1979-2009." Social Forces 91 (4): 1117-46.

Lazear, Edward P, and Sherwin Rosen. 1990. "Male-Female Wage Differentials in Job Ladders." Journal of Labor Economics 8 (1, Part 2): S106-S123.

Le Grand, Carl, and Michael Tåhlin. 2002. "Job Mobility and Earnings Growth.” European Sociological Review 18 (4): 381-400.

Longhi, Simonetta, and Alita Nandi. 2014. A Practical Guide to Using Panel Data. Sage.

Lup, Daniela. 2018. "Something to Celebrate (or Not): The Differing Impact of Promotion to Manager on the Job Satisfaction of Women and Men." Work, Employment and Society 32 (2): 407-25.

Rabe-Hesketh, Sophia, and Anders Skrondal. 2008. Multilevel and Longitudinal Modeling Using Stata. STATA press.

Reichelt, Malte, and Martin Abraham. 2017. "Occupational and Regional Mobility as Substitutes: A New Approach to Understanding Job Changes and Wage Inequality." Social Forces 95 (4): 1399-1426.

Rose, David, and Eric Harrison. 2010. "Social Class in Europe." An Introduction to the European SocioEconomic Classification.

Schmelzer, Paul. 2010. "The Consequences of Job Mobility for Future Earnings in Early Working Life in Germany - Placing Indirect and Direct Job Mobility into Institutional Context." European Sociological Review 28 (1): $82-95$.

. 2012. "The Consequences of Job Mobility for Future Earnings in Early Working Life in GermanyPlacing Indirect and Direct Job Mobility into Institutional Context." European Sociological Review 28 (1): $82-95$.

Schmelzer, Paul, and others. 2011. "Consequences of Job Mobility for the Subsequent Earnings at the Beginning of the Employment Career in Germany and the Uk." Schmollers Jahrbuch-Zeitschrift Fur Wirtschafts Und Sozialwissenschaften 131 (2): 327.

Sørensen, Aage B. 1975. "The Structure of Intragenerational Mobility." American Sociological Review, 456-71. $965-78$. 1977. "The Structure of Inequality and the Process of Attainment." American Sociological Review,

Thurow, Lester C. 1975. Generating Inequality. Basic books.

Turunen, Jarkko. 2004. "Leaving State Sector Employment in Russia." Economics of Transition 12 (1): $129-52$. 